\title{
Distributed Encoding and Retrieval of Spatial Memory in the Hippocampus
}

\author{
May-Britt Moser and Edvard I. Moser \\ Department of Psychology, Norwegian University of Science and Technology, 7034 Trondheim, Norway
}

To determine whether memory is processed in a localized or distributed manner by the hippocampus, we inactivated small regions of the structure in pretrained rats before a retention test. Ibotenic acid-induced lesions removing 40\% of the hippocampal tissue disrupted retrieval of spatial memory in a water maze but failed to affect new learning or retrieval of a task that was acquired postoperatively. Partial inactivation of the hippocampus by local intrahippocampal 5-aminomethyl-3-hydroxyisoxazole muscimol infusion also impaired retrieval but not new learning. This impairment was temporary; infusions had no effect on retrieval of predrug performance when the test was conducted $48 \mathrm{hr}$ after the

Considerable evidence points to the hippocampus as a brain structure of importance for encoding and retrieval of explicit memory (Squire, 1992; Schacter and Tulving, 1994; Eichenbaum, 1997). The mnemonic role of the hippocampus is particularly clear in tasks in which subjects are required to remember location (O'Keefe and Nadel, 1978). Hippocampal lesions disrupt acquisition and retrieval of spatial maze tasks in rats (Jarrard, 1978; Morris et al., 1982, 1990), and principal cells in the rat hippocampus fire in a location-specific manner during exploration of spatial environments (O’Keefe and Nadel, 1978; Muller, 1996). In humans, the right hippocampus is activated in navigation tasks in which retrieval of spatial relations is essential (Maguire et al., 1997).

A currently debated issue is whether the ensemble of neurons responsible for encoding and retrieval of a spatial learning episode is localized or distributed within the hippocampus. Based on the internal connectivity of the hippocampus, a range of theories have proposed that the hippocampus, acting as an autoassociative matrix (Kohonen, 1984; Rolls and Treves, 1997), encodes episodes and locations in a distributed manner (Marr, 1971; McNaughton and Morris, 1987; Buzsáki et al., 1990; Treves and Rolls, 1994; Hasselmo et al., 1995). However, although the hippocampus has many of the anatomical and physiological features expected of a distributed associative system, there is a lack of behavioral evidence for distributed function. The strongest piece of evidence is perhaps the nontopographic representation of location by hippocampal principal cells, with cells coding for the same location being distributed over the entire hippocampus

Received May 26, 1998; revised June 18, 1998; accepted June 29, 1998.

This work was supported by Norwegian Research Council Grants 115013/310, 115015/310, and 122512/310. We thank Drs. L. R. Squire and K. A. Krobert for helpful comments on an earlier version of this manuscript and A. K. Amundgaard, K. Barmen, G. Dyb, K. Haugen, and R. Pedersen for technical assistance.

Correspondence should be addressed to May-Britt Moser or Edvard I. Moser, Norwegian University of Science and Technology, 7034 Trondheim, Norway. Copyright (C) 1998 Society for Neuroscience $0270-6474 / 98 / 187535-08 \$ 05.00 / 0$ infusion. Systematic variation of the volume of dorsal and ventral hippocampal lesions showed that successful retrieval required the integrity of the entire dorsal $70 \%$ of the hippocampus. Our data suggest that although spatial tasks can be acquired with local ensembles of hippocampal neurons when other parts of the hippocampus are inactivated, spatial memory is normally both encoded and retrieved by a widely distributed hippocampal network.

Key words: spatial learning; memory; hippocampus; water maze; rat; distributed network; septotemporal; dorsal hippocampus; muscimol

(O'Keefe and Nadel, 1978; Jung et al., 1994; Poucet et al., 1994). However, location can nevertheless be predicted at high accuracy from the spatial correlates of a local cluster of hippocampal neurons (Wilson and McNaughton, 1993), suggesting that the neuronal elements required for representing an environment may exist within quite circumscribed regions of the hippocampus.

The size of the network involved in a hippocampus-dependent learning task can be determined by partial lesions or partial inactivation of the hippocampus. It has been shown previously that small blocks of the hippocampus $(\leq 25 \%)$ are sufficient for learning a reference memory task in a water maze, provided that the block is located within the dorsal two-thirds of the hippocampus (Moser et al., 1993, 1995, 1997). This suggests that spatial learning may take place with a fairly concentrated cluster of neurons. However, it is conceivable that the cells participating in encoding of memory for location are more distributed when the entire hippocampus is available, as it is in the normal rat. To explore this possibility, we first trained rats in a water maze task and then lesioned or temporarily inactivated parts of the hippocampus. We found that retrieval, but not new learning, was disrupted by restricted bilateral lesions at either side of the dorsal two-thirds of the hippocampus. The results suggest that although spatial tasks can be acquired with a small hippocampal remnant, a widely distributed hippocampal network is used for encoding and retrieval in normal rats.

\section{MATERIALS AND METHODS}

Subjects. One hundred forty-three naïve male Long-Evans rats (300-450 $\mathrm{gm})$ were housed in groups of four to six in large transparent polycarbonate cages $(59 \times 38 \times 20 \mathrm{~cm})$ with food and water available ad libitum. They were kept on a $12 \mathrm{hr}$ light/dark schedule and tested in the light phase. The animals received either a bilateral partial lesion of the hippocampus or bilateral intrahippocampal injection of the $\mathrm{GABA}_{\mathrm{A}}$ receptor agonist 5-aminomethyl-3-hydroxyisoxazole (muscimol). Control animals received sham lesions or intrahippocampal saline infusions, respectively.

Behavioral training. All rats were trained in a water maze (Morris, 
1984): a white circular polyvinylchloride tank (198 cm in diameter, $50 \mathrm{~cm}$ deep) filled to a depth of $40 \mathrm{~cm}$ with water at $25 \pm 2{ }^{\circ} \mathrm{C}$. Latex liquid was added to make the water opaque. A pneumatically controlled escape platform (11 cm in diameter) was located in the center of the southwest quadrant and could be moved by remote control between an available level $(1.5 \mathrm{~cm}$ below the water surface) and an unavailable level $(22 \mathrm{~cm}$ below the surface). The pool was located in a room $(4 \times 7 \mathrm{~m})$ with multiple cues on all sides. A wall separated the pool from the experimenter during the trials.

Unless otherwise indicated, the rats were trained to asymptotic performance before surgery. Training consisted of 11 sessions of four consecutive trials each. One session was conducted in the morning and one in the evening over a period of $6 \mathrm{~d}$, except for the first day when the rats received only one session. In each trial, the rats were released from one of eight equally spaced start positions along the perimeter of the pool in a predetermined and pseudorandom order. The position of the hooded rat during swimming was identified and stored at $10 \mathrm{~Hz}$ by a tracking system (HVS Image, Hampton, UK; Watermaze Software, Edinburgh, UK). If the rats had not entered the platform after $120 \mathrm{sec}$, they were guided onto it. The rats were left for $30 \mathrm{sec}$ on the platform. On the last day of pretraining, only a spatial probe test was conducted. The platform was kept in its lower position for the first $60 \mathrm{sec}$ of the test and the search pattern was recorded. The platform was subsequently raised to its upper accessible position, after which the rat usually found the platform. The rats were released from the quadrant opposite to the platform on the probe test. They were ranked, matched, and assigned to surgery or drug groups according to the proportion of time they spent around the platform.

Seven days after completion of pretraining and surgery, a retention test was conducted. Again, the platform was kept in its lower position for the first $60 \mathrm{sec}$, and the swim pattern was recorded. Immediately afterward, new walls and landmarks were placed around the pool and the rats were retrained with the platform in a new location. Training in the new environment consisted of four blocks of two trials each. The blocks were separated by $1 \mathrm{hr}$ intervals in lesioned animals and by $10 \mathrm{~min}$ intervals in drug-inf used animals. After the last block, another spatial probe test was conducted.

Surgery. Within $36 \mathrm{hr}$ after completion of pretraining, the rats were anesthetized with equithesin (pentobarbital and chloral hydrate; 1.0 $\mathrm{ml} / 250 \mathrm{gm}$ body weight). Hippocampal lesions were made by bilateral injection of ibotenic acid (Biosearch Technologies, San Rafael, CA) at $\leq 28$ sites (Jarrard, 1989). Ibotenic acid was dissolved in $10 \mathrm{mg} / \mathrm{ml} \mathrm{PBS,}$ $\mathrm{pH} 7.4$, and injected with a $1 \mu$ l Hamilton syringe mounted to the stereotaxic frame. Injections of $0.05-0.10 \mu \mathrm{l}$ were made over $10-20 \mathrm{sec}$ at each site. The syringe was retracted $2 \mathrm{~min}$ after injection. In shamoperated rats, the syringe was lowered through the neocortex, but no drug was infused. In three separate rats, EEGs $(0.2 \mathrm{sec}$ epochs at $30 \mathrm{sec}$ intervals) were recorded from the dorsal hippocampus after ventral ibotenic acid infusions for 5-9 hr until anesthesia had worn off. Afterdischarges (which could lead to damage outside the injected area) were not observed.

Temporary inactivation. A subset of the rats $(n=32)$ did not receive lesions but were implanted with two 26 ga guide cannulas (C315G; Plastics One), one above the dorsal pole of each hippocampus $(3.0 \mathrm{~mm}$ behind bregma, $2.2 \mathrm{~mm}$ lateral, $1.0 \mathrm{~mm}$ below dura). Cannulas and anchor screws were encased in dental acrylic. Seven days after surgery,

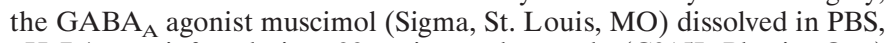
pH 7.4, was infused via a 33 ga internal cannula (C315I; Plastics One) with the tip protruding $1.0 \mathrm{~mm}$ beyond the guide cannulas. A total of 0.07 $\mu \mathrm{g}$ of muscimol in $0.14 \mu \mathrm{l}$ was injected into each hippocampus at 0.15 $\mu \mathrm{l} / \mathrm{min}$ (controlled by a syringe pump). Control rats $(n=11)$ received saline (same volume and same rate). The internal cannula was retracted 4 min after each infusion. Retention was tested 20 min later. A separate group $(n=8)$ received the muscimol $48 \mathrm{hr}$ before the retention test.

Histology. The rats were killed with an overdose of equithesin and perfused intracardially with saline and $4 \%$ formaldehyde. The brains were stored in formaldehyde for $\geq 1$ week. Frozen sections were cut coronally $(30 \mu \mathrm{m})$ and stained with cresyl violet. To determine the volume of residual hippocampal tissue in the lesioned animals, the sections were placed under a microscope attached to a video camera and a personal computer. Images were grabbed by GrabIt (AIMS Lab) and taken into Canvas (Deneba Systems), where an outline of remaining hippocampal tissue was traced. The area of the outlined region was determined by Canvas. Volume of hippocampal tissue was calculated by treating the hippocampal remnant as a series of truncated cones with parallel surfaces, in which each surface corresponded to one section and the area of the surface was equal to the area inside the outline. The volume of the hippocampal remnant was expressed as percentage of the mean volume of hippocampal tissue in the sham-operated group. Such volume estimates have been shown previously to be highly reliable, with interobserver reliabilities >0.99 (Moser et al., 1995).

\section{RESULTS}

\section{Effects of partial hippocampal lesions on retrieval and new learning}

The effect of small lesions in the hippocampus on encoding and retrieval was investigated in 42 rats that had been pretrained in a Morris water maze. During pretraining, all of these rats learned to swim directly to the hidden platform well before training was completed (Fig. 1A). On the last day of pretraining, a spatial probe test with the platform unavailable at the bottom of the pool was conducted. The animals spent most of the trial searching within a small zone around the platform (Fig. $1 B$ ). They were ranked according to time spent in the platform zone, matched, and assigned to three groups, which received (1) partial hippocampal lesions starting from the ventral pole, (2) complete hippocampal lesions, or (3) sham surgery. Surgery started $1 \mathrm{hr}$ after the probe test.

The partial hippocampal lesions encompassed nearly all hippocampal tissue from the ventral pole of the structure up to the level of the lateral geniculate nucleus (Fig. 2). The lesions spared $60.7 \pm 2.5 \%$ (mean \pm SEM) of the total hippocampal volume. The border between damaged and healthy tissue was sharp, implying that the density of intact neurons within the remaining dorsal hippocampus was within the normal range. There was partial damage to the ventral subiculum in most of the animals. Four animals were excluded because of patchy hippocampal lesions, neocortical damage, or unintended hippocampal damage (sham animal).

Retrieval was measured on a second probe test $7 \mathrm{~d}$ after pretraining and surgery (Fig. $1 C$ ). Only the sham-operated group clearly searched more within a circular zone $(35 \mathrm{~cm}$ radius) around the platform than in corresponding zones of the other quadrants. Although each zone covered $12.5 \%$ of the pool, these animals spent $35.0 \pm 3.8 \%$ (mean \pm SEM) of the search period in the platform zone. Rats with partial or complete hippocampal lesions failed to show any preference for the platform zone $(15.1 \pm 2.2 \%$ and $5.8 \pm 1.8 \%$, respectively). The short time spent around the platform in the complete lesion group was attributable to swimming near the start position opposite to the platform quadrant at the beginning of the trial. A repeated measures ANOVA of time spent in the four quadrant zones showed a significant Groups $\times$ Zones effect $\left(F_{(6,87)}=9.2 ; p<0.001\right)$ with significant group differences in the target zone $\left(F_{(2,31)}=19.7 ; p<\right.$ 0.001 ). Subsequent planned orthogonal comparisons showed that the rats with partial or complete lesions had lower target zone times than the sham-operated controls $\left(F_{(1,31)}=39.2 ; p<0.001\right)$, whereas the lesioned groups themselves did not differ $\left(F_{(1,31)}=\right.$ $3.0 ; p>0.05$ )

The ability of the above rats to learn a new task was tested on the same day by training them in a new environment. The same partially lesioned animals now performed as well as the sham group. At the end of four blocks of training, both groups had escape latencies $<15 \mathrm{sec}$ (Fig. $1 \mathrm{~A}$ ), and on a subsequent probe test, both groups searched primarily in the platform zone (Fig. $1 D)$. Rats with complete hippocampal lesions still failed to show any preference for the target area. There was a significant Groups effect on the escape latencies $\left(F_{(6,87)}=3.7 ; p<0.005\right)$ and a 


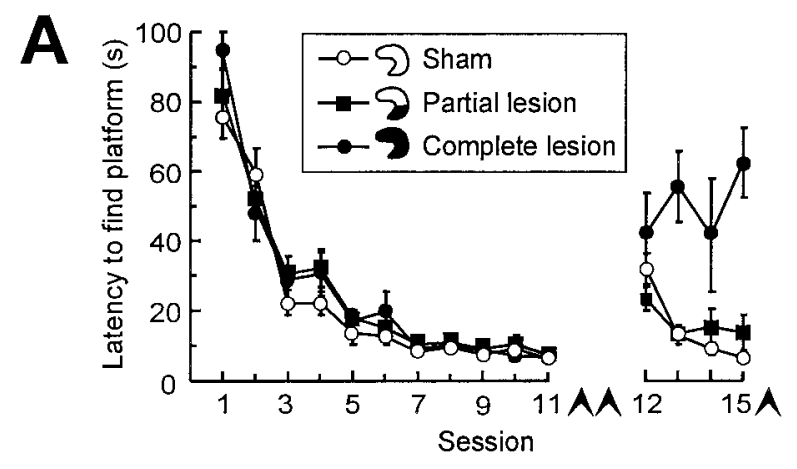

B Before surgery:
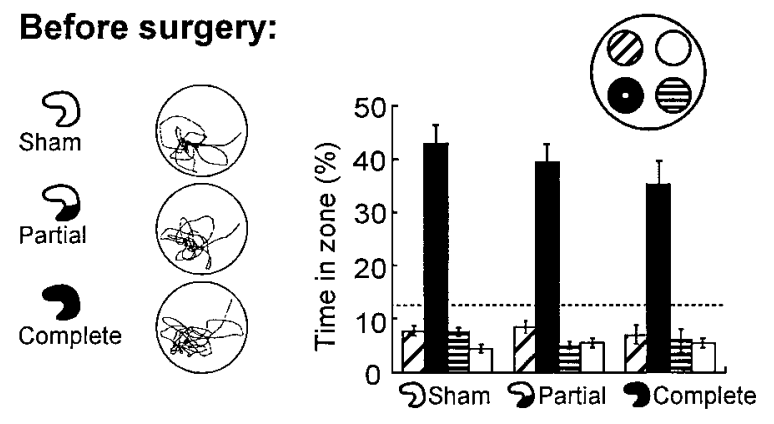

C After surgery:
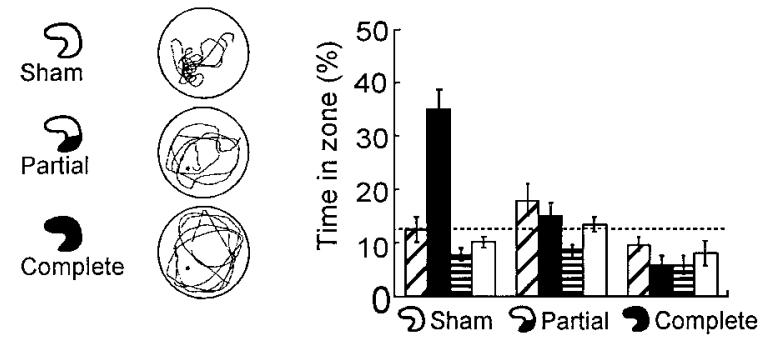

D New learning:
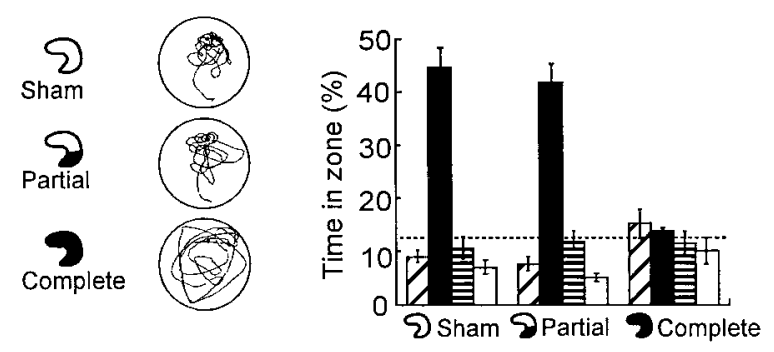

Figure 1. Retrieval of spatial memory in a water maze after a small hippocampal lesion. Control groups received sham surgery or complete hippocampal lesions. Lesions were induced after 11 sessions of pretraining. Seven days later, retrieval was tested, and the animals were trained in a new task. $A$, Latency to locate the hidden platform before surgery (sessions 1-11) and after surgery (sessions $12-15$, conducted in a new environment). Arrowheads indicate spatial probe tests. $B-D$, Retrieval on probe tests at the end of pretraining $(B), 7 \mathrm{~d}$ after pretraining and surgery $(C)$, and after postoperative training in the new environment $(D)$. Left column, Typical swim paths. Right column, Time spent in a circular zone around the platform position ( filled bars) and in corresponding zones of the three other quadrants (mean $\pm \mathrm{SEM}$ ). Chance level is $12.5 \%$ (dashed lines). significant Groups $\times$ Zones effect on time distribution on the probe test $\left(F_{(6,87)}=10.0 ; p<0.001\right)$. Both effects reflected the difference between the complete lesion group and the two other groups. The preservation of spatial learning in rats with the dorsal $60 \%$ of the hippocampus intact is consistent with previous observations (Moser et al., 1995) and argues for adequate function of the spared hippocampal tissue.

To further rule out nonspecific factors related to incomplete recovery from surgery on the retention test on day 7 , separate groups with similar lesions were tested for retention $16 \mathrm{~d}$ after surgery $(n=23)$. In the partial lesion group, $56.6 \pm 1.6 \%$ of hippocampal volume was spared, with the lesion starting at the ventral end of the hippocampus. The same differential behavior was observed as after $7 \mathrm{~d}$. The rats spent $31.0 \pm 3.7 \%$ (sham surgery), $17.2 \pm 2.1 \%$ (partial lesions), and $9.1 \pm 2.9 \%$ (complete lesions) of the search time in the platform zone (Groups $\times$ Zones effect, $\left.F_{(6,60)}=3.2 ; p<0.01\right)$.

\section{Relationship between volume of hippocampal tissue and success of retrieval}

The fact that retrieval of a spatial task was impaired after a lesion confined to the ventral half of the hippocampus was surprising, because ventral lesions have no effects on encoding (Moser et al., 1993, 1995). The ventral hippocampus might be a central part of the substrate for retrieval but not for encoding. Alternatively, both encoding and retrieval rely primarily on the dorsal hippocampus, but the area used for retrieval might be larger and thus stretch well into the ventral half of the hippocampus (and into the damaged region of rats with ventral lesions). To dissociate effects of location from effects of volume, we pretrained rats to asymptotic performance (as above) and made additional lesions sparing a broader range of hippocampal volume. Lesions were now made from either the ventral end of the hippocampus (as above) or from the dorsal end. In total, 100 rats received surgery (including the rats of the first experiment). Sixty-one of these received dorsal $(n=39)$ or ventral $(n=22)$ hippocampal lesions.

The partial lesions were confined to either the dorsal or the ventral hippocampus. The volume of the dorsal remnants ranged from 41 to $91 \%$ of total hippocampal tissue, whereas the ventral remnants ranged from 27 to $92 \%$. Ventral hippocampal lesions were associated with some ventral subicular damage. Seven animals with dorsal remnants, two with ventral remnants, three with complete lesions, and three sham-operated animals were excluded because of unintended neocortical or thalamic damage or because of patchy hippocampal lesions.

Successful retrieval $7 \mathrm{~d}$ after pretraining and surgery was observed only with the largest volumes of spared dorsal hippocampal tissue (Fig. 3). In the group with dorsal remnants, those with $>60 \%$ of the hippocampus intact preferred the platform zone to the other zones, but only those with $>70 \%$ were comparable to the sham rats (sham group vs $60-70 \%$ group, $t_{(31)}=3.4$; $p<0.005$; sham group versus $>70 \%$ group, $\left.t_{(26)}=1.5 ; p>0.05\right)$. In the group with ventral remnants, rats with $<70 \%$ intact performed at random, whereas rats with $>70 \%$ showed some retention but still significantly less than the sham group $\left(t_{(29)}=3.1 ; p<\right.$ $0.005)$. There were no group differences in behavior during the pretraining. Thus, rats need at least $70 \%$ of the hippocampus to retrieve a spatial task that is encoded preoperatively. These $70 \%$ must be at the dorsal side of the structure.

\section{Reversibility of the retrieval deficit}

We investigated whether the retrieval deficit was reversible by inactivating a small portion of the dorsal hippocampus with the 
Figure 2. Location of remaining hippocampal tissue in a rat with a partial hippocampal lesion that impaired retrieval but not new learning (Fig. 1). $A$, Coronal section showing cresyl violet stains of neuronal cell bodies in the intermediate to ventral portion of the hippocampus of a sham-operated rat (left) and a rat with a lesion that spared $58.5 \%$ of hippocampal volume dorsally (right). Arrowheads indicate border between lesioned and healthy tissue. $B$, Threedimensional reconstruction of the remaining dorsal hippocampal tissue (white) of the lesioned rat in $A$ superimposed on a reconstruction of the entire hippocampus ( gray).
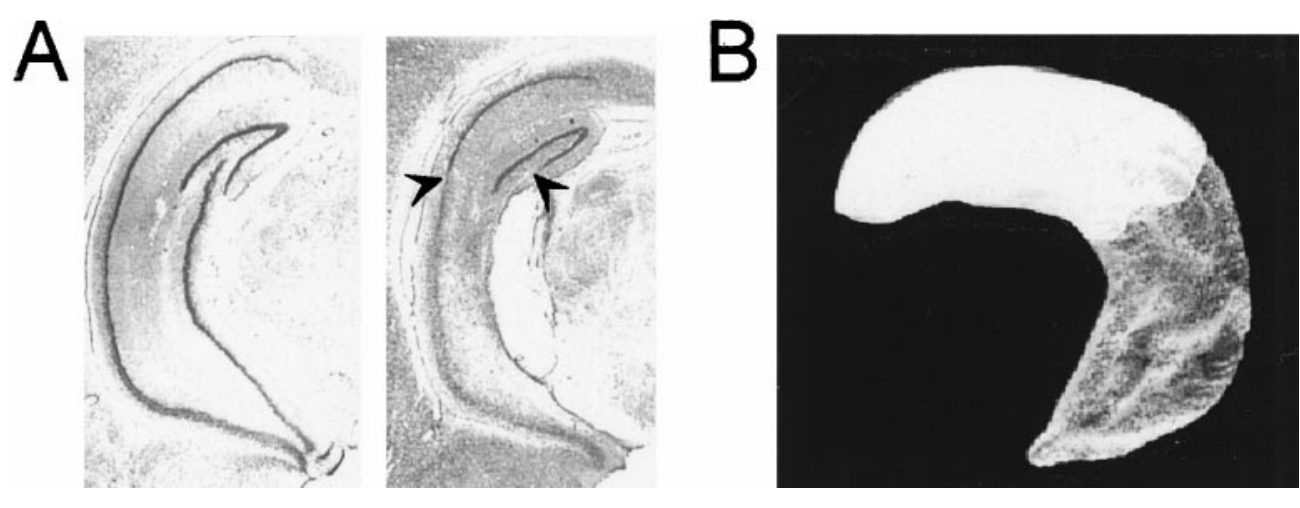

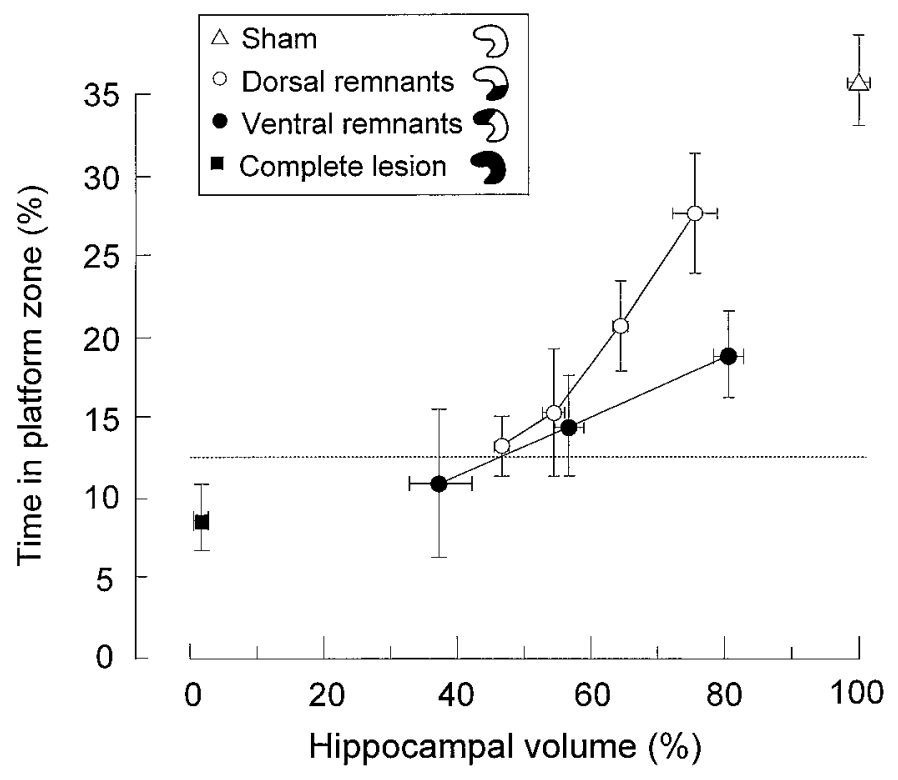

Figure 3. Retrieval on a spatial probe test $7 \mathrm{~d}$ after pretraining and surgery as a function of remaining hippocampal volume in animals with dorsal remnants ( $10 \%$ bins) or ventral remnants (20\% bins). Retrieval is expressed as the proportion of time spent in a circular zone around the platform position (mean \pm SEM). Dashed line indicates chance level.

$\mathrm{GABA}_{\mathrm{A}}$ agonist muscimol in a separate set of animals $(n=32)$, all pretrained to asymptotic performance in the water maze (Fig. $4 A)$. All rats showed a preference for the zone around the platform on the probe test at the end of training (Fig. 4B). The infusion cannulas were placed within the dorsal one-third of the hippocampus on both sides of the brain (Fig. 5). The amount of hippocampal damage was $<0.2 \%$. In two animals, the cannulas did not hit the hippocampus; these animals were excluded from further analysis. Three animals were excluded because of cortical lesions or infection.

Seven days after pretraining and implantation, the animals were tested for retrieval of the spatial task. Twenty minutes before testing, they received an intrahippocampal infusion of either saline or a low dose of muscimol. In a separate group, muscimol was infused $48 \mathrm{hr}$ before the retrieval test; thus, little or no drug was left in the brain at the time of testing. Rats tested with muscimol at the 20 min interval swam no more in the platform zone than in the corresponding zones of the other quadrants (Fig. 4C). In contrast, rats tested at $48 \mathrm{hr}$ clearly preferred the platform zone, as did the saline-infused animals, suggesting that the retrieval impairment was reversible. ANOVA of the probe test times showed a significant Groups $\times$ Zones effect $\left(F_{(6,72)}=4.2 ; p<0.001\right)$ and a significant Groups effect on time in the platform zone $\left(F_{(2,26)}=7.7 ; p<0.005\right)$. Planned orthogonal comparisons showed that the muscimol 20 min group spent less time in the target zone than the saline and muscimol 48 hr groups $\left(F_{(1,26)}=15.4 ; p<0.001\right)$, whereas the two latter groups did not differ $(F<1)$.

All three groups were able to acquire a navigation task in a new environment during the subsequent hour. In all groups, the rats learned to swim to the hidden platform within $\sim 15 \sec$ (Fig. $4 A$ ). On the final probe test in the new environment, all three groups showed a preference for the platform zone (Fig. 4D). There was no significant Groups effect on escape latencies, nor was there a Groups $\times$ Z ones effect on the probe test $(F$ values $<1.3)$. Thus, temporary inactivation of a small part of the hippocampus disrupted retrieval but not new learning.

\section{Retrieval after postoperative training}

Our data suggest that retrieval relies on a widespread hippocampal network. The reason could be that a widely distributed network was engaged during encoding and that the same distributed network must be activated for retrieval of the stored information. Alternatively, the need for large portions of the hippocampus may be inherent to the retrieval process itself, i.e., retrieval may require processes that were not involved in original encoding. If the latter is true, small lesions may disrupt retrieval regardless of the amount of hippocampus used for acquisition. Thus, we tested 20 rats that had acquired the water maze task after partial hippocampal lesions were made. The lesions of these rats were similar to those of the rats learning the task before surgery, with $62.3 \pm 1.9 \%$ of total hippocampal volume being spared at the dorsal end.

As expected, both the rats with small hippocampal lesions and the sham-operated rats learned to find the hidden platform rapidly and precisely (Fig. 6A). These groups achieved escape latencies $<10 \mathrm{sec}$ and clearly searched in the area around the platform on the probe test at the end of the training (Fig. $6 B$ ). In contrast, a group of rats with complete hippocampal lesions failed to learn where the platform was located. There was a significant effect of Groups on the escape latencies $\left(F_{(2,17)}=47.3 ; p<0.001\right)$, as well as a Groups $\times$ Zones effect on time spent in the four zones on the probe test $\left(F_{(6,51)}=5.7 ; p<0.001\right)$. Both effects reflected the difference between the group with complete lesions and the two other groups.

When tested for retention $7 \mathrm{~d}$ later, both the sham-operated and the partially lesioned animals searched in the target zone, 
A

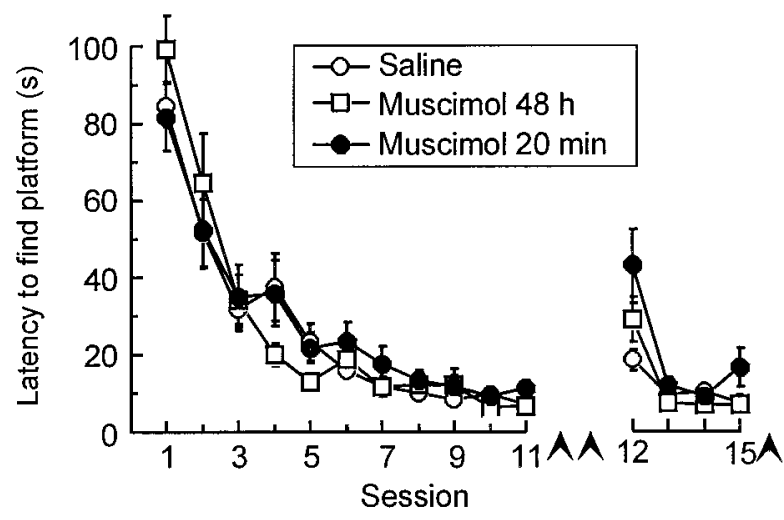

\section{B Before surgery:}
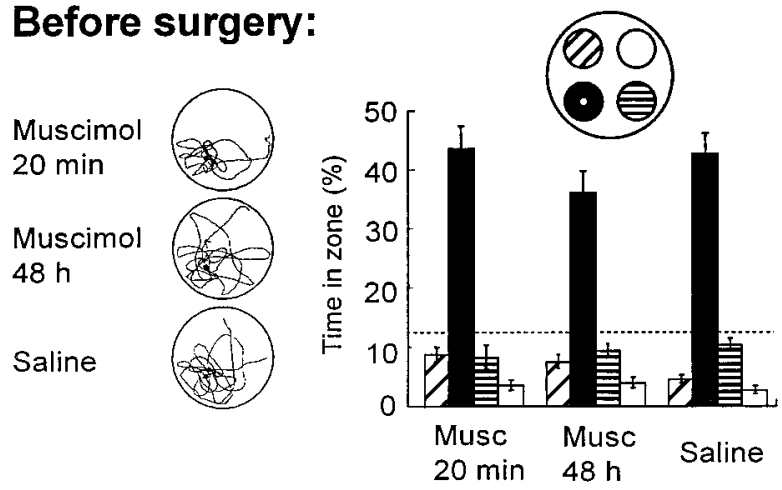

\section{After surgery:}
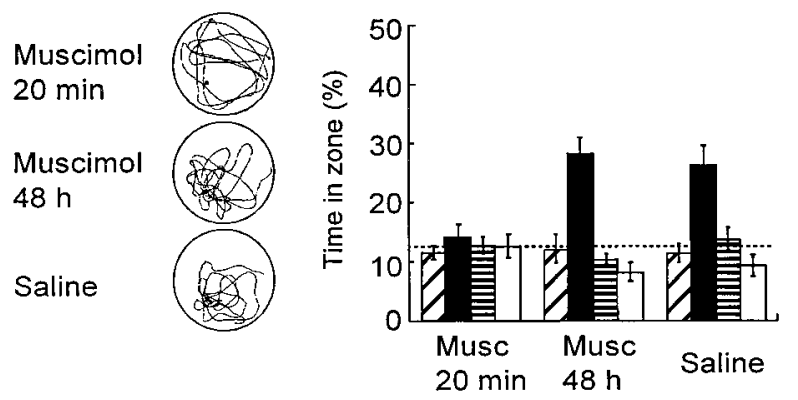

\section{New learning:}
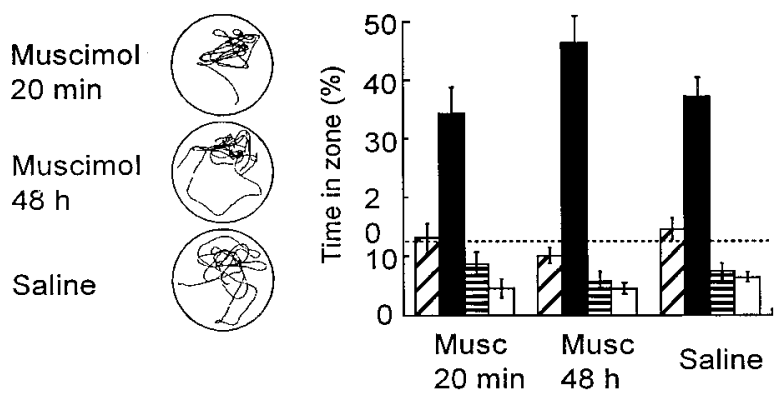

Figure 4. Distribution of swim time in pretrained rats after partial inactivation of the dorsal hippocampus by microinf usion of the $\mathrm{GABA}_{\mathrm{A}}$ receptor agonist muscimol. The interval between pretraining and drug infusion was $7 \mathrm{~d}$. $A$, Latency to locate the hidden platform during pretraining (sessions $1-11$ ) and after drug infusion (sessions $12-15$, con- whereas rats with complete hippocampal lesions still failed on both tests (Fig. 4B). Again, there was a significant Groups $\times$ Zones effect $\left(F_{(6,51)}=5.7 ; p<0.001\right)$ and a significant Groups effect on time in the platform zone $\left(F_{(2,19)}=11.3 ; p<0.001\right)$. Orthogonal comparisons showed a difference between rats with total hippocampal damage and rats with either partial lesions or no lesions at all $\left(F_{(1,19)}=22.3 ; p<0.001\right)$. There was no difference between the partial lesion group and the sham group $(F$ $<1$ ). Thus, less hippocampal tissue was needed for retrieval if the task was acquired after the partial hippocampal lesion.

\section{DISCUSSION}

The present study shows that retrieval of spatial memory is disrupted by small lesions within the dorsal $70 \%$ of the hippocampus in rats trained before surgery. Retrieval was not impaired if acquisition occurred subsequent to the partial lesions, although the interval between training and retrieval was similar. The lesions had no effect on new learning. The results suggest that a widespread hippocampal network is used in normal rats during encoding and retrieval of spatial memory, that this network is located within the dorsal $70 \%$ of the hippocampus, and that smaller networks within this region can be used for encoding in rats with partial hippocampal lesions.

\section{Dissociation between retrieval and new learning}

Small hippocampal lesions impaired retrieval, suggesting that retrieval involves a widespread hippocampal network. This interpretation rests on the assumption that the remaining hippocampal tissue functioned normally. It is conceivable that ibotenic acid disrupted information processing also in the noninjected parts of the hippocampus, e.g., by triggering seizures. However, the tissue remnants seem to be normal in several important respects. Both synaptic activation and short- and long-term plasticity in the main excitatory synapses of such blocks have been shown to be within the normal range (Moser et al., 1995), and the animals seem to be capable of normal spatial learning in a water maze. Moreover, temporary inactivation of a part of the hippocampus impaired retrieval shortly after the infusion but not $2 \mathrm{~d}$ later when the drug presumably had disappeared from the synapses. Thus, access to spatial memory seems to reappear in the muscimol-inf used animals, and it is unlikely that the selective disruption of retrieval after partial inactivation or lesions of the hippocampus reflects damage to the hippocampal network. Rather, we believe pretrained animals were impaired, because a substantial volume of the hippocampus was required for retrieval of spatial memory.

Although retrieval was disrupted, new learning was unimpaired in the partially lesioned rats. Rats with partial damage acquired a new spatial task at the same rate as sham-operated animals. Together with previous observations (Moser et al., 1993, 1995, 1997), this suggests that relatively small pieces of dorsal hippocampal tissue (a quarter or less of total hippocampal volume) are sufficient to encode a representation that successfully guides the rat toward a hidden goal. If less than a quarter of the

ducted in a new environment). Arrowheads indicate spatial probe tests. $B-D$, Retrieval on probe tests at the end of preoperative training $(B), 7 \mathrm{~d}$ after pretraining and surgery $(C)$, and after new learning in a different environment $1.2 \mathrm{hr}$ subsequent to the test in $C(D)$. Muscimol was infused $20 \mathrm{~min}$ or $48 \mathrm{hr}$ before the test in $C$. A separate group received saline 20 min before testing. No drug was given in B. Left column, Typical swim paths. Right column, Time spent in the central zones of each quadrant (Fig. 1). Dashed lines indicate chance level. 
Figure 5. Location of the muscimol infusion within the dorsal hippocampus. $A, \mathrm{Cr}$ esyl violet stain showing position of internal cannula (arrowhead) in the hippocampus of a representative muscimol-infused rat. The neocortical damage was attributable to the implanted guide cannula. $B$, Threedimensional reconstruction showing the position of the cannula (asterisk) in one hippocampus of the same rat.
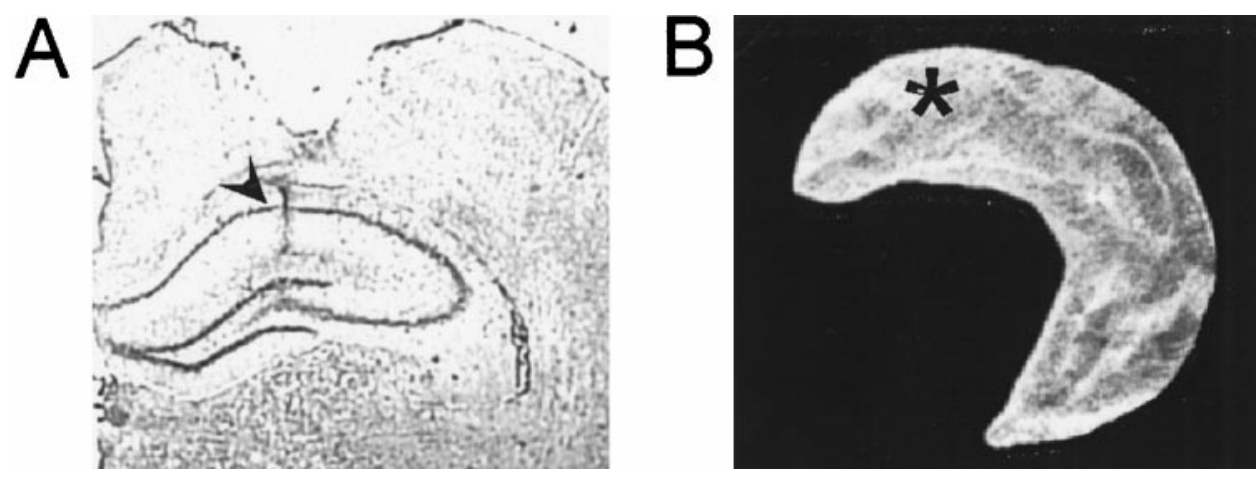

hippocampus (half of the dorsal hippocampus) is left intact, new learning is also affected (Moser et al., 1995; Duva et al., 1997).

In animals familiar with the procedural rules of the water maze, knowledge of a new platform position can be acquired within a single trial (Morris et al., 1986). The present data demonstrate such fast learning also in rats with partial hippocampal lesions, even when the rats do not remember the spatial layout of the original training environment. This is consistent with previous work showing that relearning in radial mazes after large neurotoxic lesions of the hippocampus is only mildly disrupted (Handelmann and Olton, 1981; Jarrard, 1986) and suggests that procedural knowledge about the water maze task is stored and accessed outside the hippocampus (Morris et al., 1982, 1986; Squire, 1992).

The observation that larger volumes of hippocampal tissue are required for retrieval than for new learning may be surprising, because in many regions of the cortex, repetition and practice are accompanied by reduced neuronal activation in specific areas. Well practiced normal subjects show such reductions during perceptual and conceptual priming (Squire et al., 1992; Raichle et al., 1994; Buckner et al., 1998), during recall of familiar stories and word lists (Andreasen et al., 1995a,b), and during motor behavior (Petersen et al., 1998). In primates, single neurons in the inferior temporal and rhinal cortices respond less frequently to the second than to the first presentation of a stimulus (Miller et al., 1991; Riches et al., 1991), although this does not necessarily imply that the activated area becomes smaller. In the hippocampus, discharge probabilities were not reduced by repeated presentations (Riches et al., 1991), suggesting that many hippocampal neurons that were active during encoding may be required also for retrieval.

\section{The hippocampal volume required for retrieval mirrors the volume used for original encoding}

Encoding and retrieval of episodic memory may be associated with differential patterns of activity. There is only partial overlap between the systems activated during these processes in the neocortex (Tulving and Markowitsch, 1997; Fletcher et al., 1997). A similar differentiation may exist for spatial memory within the hippocampus, in which case the need for large volumes of hippocampal tissue during retrieval could be a property of retrieval per se rather than a consequence of the way memory was encoded.

Our data suggest that the amount of hippocampal tissue required for retrieval of a spatial task is not fixed but rather reflects the volume of hippocampal tissue with which the task was acquired. If only a block of the dorsal hippocampus was present during training, that small block also appeared to be sufficient for subsequent retrieval (Fig. 6), probably because the necessary cellular modifications took place within that block. If the rats learned the spatial task with an intact brain, however, successful retrieval required $\geq 70 \%$ of the hippocampus (Figs. 1, 3), suggesting that a widely distributed network was engaged during encoding. Thus, in normal rats, a widespread neuronal ensemble may be engaged both during encoding and again during retrieval of the stored information. The overlapping nature of the two ensembles would be consistent with models, suggesting that the same hippocampal principal neurons may perform both encoding and retrieval functions (Paulsen and Moser, 1998).

\section{Spatial memory functions may take place in the entire dorsal $70 \%$ of the hippocampus}

At least $70 \%$ of the hippocampus was required to retrieve a spatial task encoded with an intact brain. However, retrieval was successful only if the $70 \%$ remnants were at the dorsal side of the hippocampus. Probably because the critical substrate was so large, impairment was seen also after large ventral lesions (affecting $\sim 40 \%$ of the hippocampus) (Fig. 2) as these encroached on the dorsal to intermediate area.

Encoding is possible with a minimum of preserved tissue in either the dorsal or the intermediate portion of the hippocampus but not in the ventral portion (Moser et al., 1997). Thus, the same sectors of the dorsoventral axis of the hippocampus seem to be involved in encoding and retrieval of spatial memory. Recent tracing studies have shown that sensory input likely to be important for spatial learning is distributed to the dorsal and the intermediate hippocampus but not to the ventral pole of the structure (Deacon et al., 1983; Witter et al., 1989; Dolorfo and Amaral, 1998a,b). Thus, behavioral and anatomical data converge and suggest that the hippocampus may consist of a large dorsal region involved in spatial learning and a smaller ventral region not essential for navigation.

The location of the border between the putative functional divisions of the hippocampus may have implications for the interpretation of studies investigating whether pyramidal cells have place fields not only in the dorsal hippocampus but also in the ventral hippocampus. Place cells have been reported in the ventral half of the hippocampus, although such cells may be fewer, discharge at lower rates, and have larger place fields (Jung et al., 1994; Poucet et al., 1994). However, if more than half of the hippocampus is used for navigation learning, the ventral cells with place fields may still have been located at the dorsal side of the putative border. 
A

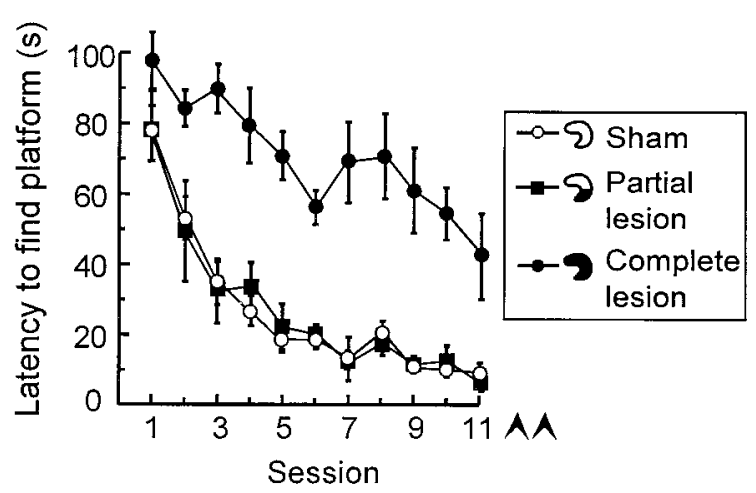

B
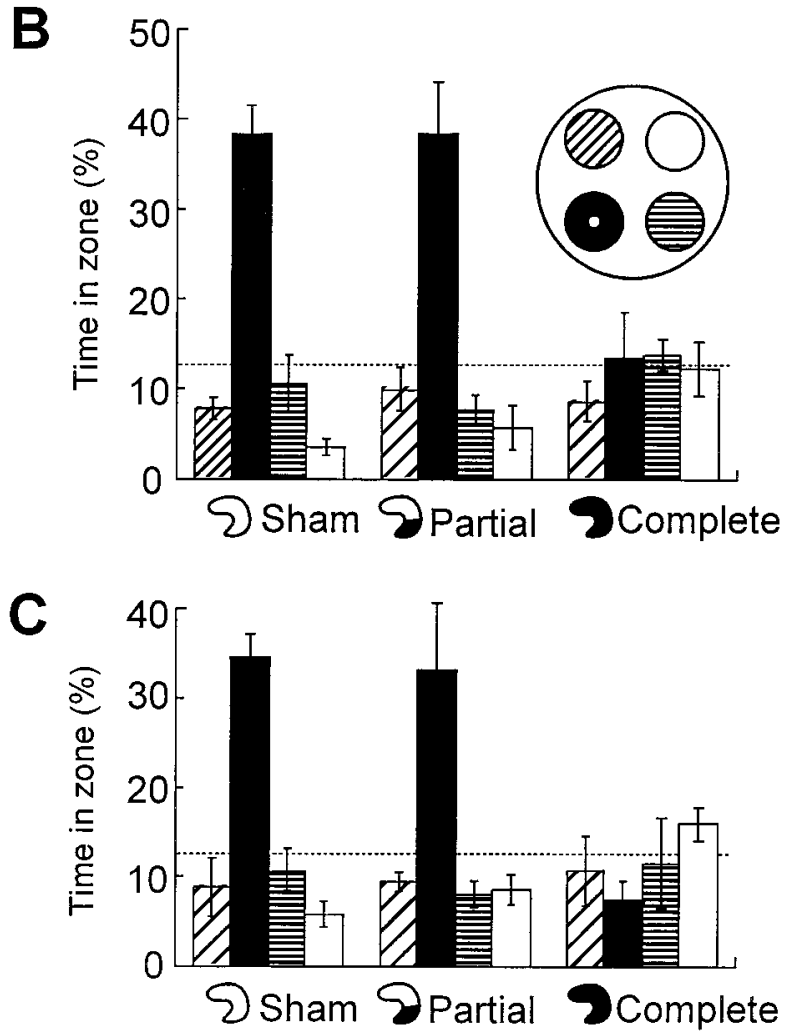

Figure 6. Retrieval in animals that received training after the partial hippocampal lesion. The rats had lesions sparing the dorsal hippocampus (as in Fig. 2), complete hippocampal lesions, or sham lesions. $A$, Latency to locate the hidden platform during postoperative training. Arrowheads indicate spatial probe tests. $B, C$, Retrieval at the end of training $(B)$ and 7 d later $(C)$. Symbols are the same as in Figure 1.

\section{Longitudinal integration of hippocampal activity during encoding and retrieval}

The representation of location by hippocampal place cells is nontopographic (O'Keefe and Nadel, 1978; Muller, 1996). A local cluster of place cells in the dorsal hippocampus usually covers most parts of a spatial environment, and the location of the animal in this environment can be predicted from the discharge pattern of these cells (Wilson and McNaughton, 1993). However, we found that retrieval was disrupted by small hippocampal lesions, which suggests that a local cluster of neurons may not be sufficient for retrieving a useful place representation. Place learning may involve associations between events that each give rise to activity at separate levels of the hippocampus. With sensory information entering the hippocampus along as much as threequarters of the longitudinal axis of the structure (Dolorfo and Amaral, 1998a,b), it is conceivable that widely separated inputs are associated during spatial learning.

Integration of signals from different levels of the hippocampus may depend on the extensive longitudinal connections of the structure (Amaral and Witter, 1989). Although the average direction of the excitatory pathways of the hippocampus is in the transverse plane (Andersen et al., 1971), the major excitatory and inhibitory connections are highly collateralized and divergent (Amaral and Witter, 1989; Tamamaki and Nojyo, 1990, 1993; Sik et al., 1995), and both dentate mossy cells and CA3 pyramidal cells have extensive associational fibers projecting widely in the longitudinal direction (Swanson et al., 1978; Ishizuka et al., 1990; $\mathrm{Li}$ et al., 1994). These recurrent collaterals provide a substrate by which input entering at multiple and distributed sites along the dorsoventral axis of the hippocampal formation could become associated during spatial learning (Marr, 1971; McNaughton and Morris, 1987; Treves and Rolls, 1994; Hasselmo et al., 1995).

\section{REFERENCES}

Amaral DG, Witter MP (1989) The three-dimensional organization of the hippocampal formation: a review of anatomical data. Neuroscience 31:571-591.

Andersen P, Bliss TVP, Skrede KK (1971) Lamellar organization of hippocampal excitatory pathways. Exp Brain Res 13:222-238.

Andreasen NC, O'Leary DS, Arndt S, Cizadlo T, Rezai K, Watkins GL, Ponto LLB, Hichwa RD (1995a) I. PET studies of memory: novel and practiced free recall of complex narratives. NeuroImage 2:284-295.

Andreasen NC, O'Leary DS, Cizadlo T, Arndt S, Rezai K, Watkins GL, Ponto LLB, Hichwa RD (1995b) II. PET studies of memory: novel versus practiced free recall of word lists. NeuroImage 2:296-305.

Buckner RL, Goodman J, Burock M, Rotte M, Koutstaal W, Schacter D, Rosen B, Dale AM (1998) Functional-anatomic correlates of object priming in humans revealed by rapid presentation event-related fMRI. Neuron 20:285-296.

Buzsáki G, Chen LS, Gage FH (1990) Spatial organization of physiological activity in the hippocampal region: relevance to memory formation. Prog Brain Res 83:257-268.

Deacon TW, Eichenbaum H, Rosenberg P, Eckmann KW (1983) Afferent connections of the entorhinal area in the rat as demonstrated by retrograde cell-labeling with horseradish peroxidase. Brain Res 152:249-264.

Dolorfo CL, Amaral DG (1998a) Entorhinal cortex of the rat: topographic organization of the cells of origin of the perforant path projection to the dentate gyrus. J Comp Neurol, in press.

Dolorfo CL, Amaral DG (1998b) Entorhinal cortex of the rat: organization of intrinsic connections. J Comp Neurol, in press.

Duva CA, Floresco SB, Wunderlich GR, Lao TL, Pinel JPJ, Phillips AG (1997) Disruption of spatial but not object-recognition memory by neurotoxic lesions of the dorsal hippocampus in rats. Behav Neurosci 111:1184-1196.

Eichenbaum H (1997) Declarative memory: insights from cognitive neurobiology. Annu Rev Psychol 48:547-572.

Fletcher PC, Frith CD, Rugg MD (1997) The functional neuroanatomy of episodic memory. Trends Neurosci 20:213-218.

Handelmann GE, Olton DS (1981) Spatial memory following damage to hippocampal CA3 pyramidal cells with kainic acid: impairment and recovery with preoperative training. Brain Res 217:41-58.

Hasselmo ME, Schnell E, Barkai E (1995) Dynamics of learning and recall at excitatory recurrent synapses and cholinergic modulation in rat hippocampal region CA3. J Neurosci 15:5249-5282.

Ishizuka N, Weber J, Amaral DG (1990) Organization of intrahippocampal projections originating from CA3 pyramidal cells in the rat. J Comp Neurol 295:580-623.

Jarrard LE (1978) Selective hippocampal lesions: differential effects on performance by rats of a spatial task with preoperative versus postoperative training. J Comp Physiol Psychol 92:1119-1127.

Jarrard LE (1986) Selective hippocampal lesions and behavior: Implications for current research and theorizing. In: The hippocampus, Vol 4 (Isaacson RL, Pribram KH, eds), pp 93-126. New York: Plenum. 
Jarrard LE (1989) On the use of ibotenic acid to lesion selectively different components of the hippocampal formation. J Neurosci Methods 29:251-259.

Jung MW, Wiener SI, McNaughton BL (1994) Comparison of spatial firing characteristics of units in dorsal and ventral hippocampus of the rat. J Neurosci 14:7347-7356.

Kohonen T (1984) Self-organization and associative memory. New York: Springer.

Li A, Somogyi P, Ylinen A, Buzsáki G (1994) The hippocampal CA3 network: an in vivo intracellular labeling study. J Comp Neurol 339:181-208.

Maguire EA, Frackowiak RSJ, Frith CD (1997) Recalling routes around London: activation of the right hippocampus in taxi drivers. J Neurosci 17:7103-7110.

Marr D (1971) Simple memory: a theory of archicortex. Philos Trans R Soc Lond B Biol Sci 262:23-81.

McNaughton BL, Morris RGM (1987) Hippocampal synaptic enhancement and information storage within a distributed memory system. Trends Neurosci 10:408-415.

Miller EK, Li L, Desimone R (1991) A neural mechanism for working and recognition memory in inferior temporal cortex. Science 254:1377-1379.

Morris RG (1984) Developments of a water-maze procedure for studying spatial learning in the rat. J Neurosci Methods 11:47-60.

Morris RG, Garrud P, Rawlins JNP, O'Keefe J (1982) Place navigation impaired in rats with hippocampal lesions. Nature 297:681-683.

Morris RG, Hagan JJ, Rawlins JNP (1986) Allocentric spatial learning by hippocampectomized rats: a further test of the "spatial mapping" and "working memory" theories of hippocampal function. Q J Exp Psychol [B] 38:365-395.

Morris RG, Schenk F, Tweedie F, Jarrard LE (1990) Ibotenate lesions of hippocampus and/or subiculum: dissociating components of allocentric spatial learning. Eur J Neurosci 2:1016-1028.

Moser EI, Moser MB, Andersen P (1993) Spatial learning impairment parallels the magnitude of dorsal hippocampal lesions, but is hardly present following ventral lesions. J Neurosci 13:3916-3925.

Moser MB, Moser EI, Forrest E, Andersen P, Morris RG (1995) Spatial learning with a minislab in the dorsal hippocampus. Proc Natl Acad Sci USA 92:9697-9701.

Moser MB, Tollefsrud A, Moser EI, Andersen P (1997) Multiple substrates for spatial learning in the rat hippocampus. Soc Neurosci Abstr 23:621.

Muller RU (1996) A quarter of a century of place cells. Neuron 17:813-822.

O'Keefe J, Nadel L (1978) The hippocampus as a cognitive map. Oxford: Clarendon.
Paulsen O, Moser EI (1998) A model of hippocampal memory encoding and retrieval: GABAergic control of synaptic plasticity. Trends Neurosci 21:273-278.

Petersen SE, van Mier H, Fiez JA, Raichle ME (1998) The effects of practice on the functional anatomy of task performance. Proc Nat Acad Sci USA 95:853-860.

Poucet B, Thinus-Blanc C, Muller RU (1994) Place cells in the ventral hippocampus of rats. NeuroReport 5:2045-2048.

Raichle ME, Fiez JA, Videen TO, MacLeod AM, Pardo JV, Fox PT, Petersen SE (1994) Practice-related changes in human brain functional anatomy during nonmotor learning. Cereb Cortex 4:8-26.

Riches IP, Wilson FA, Brown MW (1991) The effects of visual stimulation and memory on neurons of the hippocampal formation and the neighboring parahippocampal gyrus and inferior temporal cortex of the primate. J Neurosci 11:1763-1779.

Rolls ET, Treves A (1997) Neural networks and brain function. Oxford: Oxford UP.

Schacter DL, Tulving E (1994) Memory systems. Cambridge, MA: MIT.

Sik A, Penttonen M, Ylinen A, Buzsáki G (1995) Hippocampal CA1 interneurons: an in vivo intracellular labeling study. J Neurosci 15:6651-6665.

Squire LR (1992) Memory and the hippocampus: a synthesis from findings with rats, monkeys, and humans. Psychol Rev 99:195-231.

Squire LR, Ojemann JG, Miezin FM, Petersen SE, Videen TO, Raichle ME (1992) Activation of the hippocampus in normal humans: a functional anatomical study of memory. Proc Natl Acad Sci USA 89:1837-1841.

Swanson LW, Wyss JM, Cowan WM (1978) An autoradiographic study of the organization of intrahippocampal association pathways in the rat. J Comp Neurol 181:681-716.

Tamamaki N, Nojyo Y (1990) Disposition of the slab-like modules formed by axon branches originating from single CA1 pyramidal neurons in the rat hippocampus. J Comp Neurol 291:509-519.

Tamamaki N, Nojyo Y (1993) Projection of the entorhinal layer II neurons in the rat as revealed by intracellular pressure-injection of neurobiotin. Hippocampus 3:471-480.

Treves A, Rolls ET (1994) Computational analysis of the role of the hippocampus in memory. Hippocampus 4:374-392.

Tulving E, Markowitsch HJ (1997) Memory beyond the hippocampus. Curr Opin Neurobiol 7:209-216.

Wilson MA, McNaughton BL (1993) Dynamics of the hippocampal ensemble code for space. Science 261:1055-1058.

Witter MP, Groenewegen HJ, Lopes da Silva FH, Lohman AHM (1989) Functional organization of the extrinsic and intrinsic circuitry of the parahippocampal region. Prog Neurobiol 33:161-254. 